\title{
LA ESTABILIDAD LABORAL Y LA RIGIDEZ LABORAL: DOS ABERRACIONES EN LA POLÍTICA PÚBLICA PERUANA
}

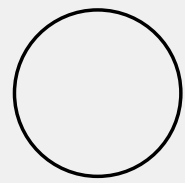

\section{RAINER S. SUMMERS}

- Profesor de Globalización

Área Académica de Administración, UPC

\section{RESUMEN}

La Estabilidad Laboral y la rigidez laboral son aberrantes porque chocan con principios elementales de la economía de libre mercado y del industrialismo. Si el Perú quiere desarrollarse industrialmente para poder enfrentar a la 4ª Revolución Industrial del siglo XXI, tiene que conocer, entender y adecuarse a las leyes de la lógica del industrialismo.

Palabras clave: Estabilidad laboral, Rigidez laboral, Desarrollo económico

\section{ABSTRACT}

Labor stability and labor rigidity are aberrant because they collide with basic principles of a free market economy and of Industrialism. If Peru wants to develop its industrial sector, in order to face the 4th Industrial Revolution of the $\mathrm{XXI}$ century, it is essential to know, understand and adapt to the principles and logic of Industrialism.

Key words: Employment stability, Employment rigidity, Economic development

La estabilidad laboral es el derecho que la ley le concede a un trabajador formal a conservar su puesto indefinidamente, no pudiendo ser declarado cesante antes de que adquiera el derecho de su jubilación, a no ser por causa taxativa y previamente determinada o por la existencia de especialísimas circunstancias que hagan imposible su continuación. La estabilidad laboral le otorga un carácter permanente a la relación de trabajo entre empleador y empleado, en que la disolución del vínculo laboral depende únicamente de la voluntad del trabajador, y, solo por excepción, de la del empleador.

"El camino del infierno está empedrado de buenas intenciones", escribió Dante Alighieri en la Divina comedia. Consideramos que, en el caso de la estabilidad laboral y de su secuela, la rigidez laboral, la cita es de plena aplicación, porque, pretendiendo hacerle un bien al país, se le inflige

1. UPC Review of Global Management, Volumen 3, Número 1, junio 2017 un grave daño, el cual es menester poner de manifiesto para que se pueda corregir, de modo que se eviten en el futuro mayores costos económicos afines.

La estabilidad laboral fue impuesta en 1970 durante el Gobierno Revolucionario de la Fuerza Armada por el general Juan Velasco Alvarado², su primer dictador, y consagrada en la Constitución Política de 1979 por orden expresa del segundo dictador de ese gobierno, el general Francisco Morales Bermúdez, a la Asamblea Constituyente de 1978³. En 1986, Alan García, como presidente constitucional, la reguló con la Ley 24514 del 31 de mayo de 1986. Alberto Fujimori, quien casi la elimina con el Decreto Legislativo 728 del 8 de noviembre de 1991, en la Constitución Política de 1993, artículo 27, la circunscribió a la protección del trabajador del despido arbitrario.

Este ensayo tiene por objeto desarrollar una discusión mediante la que calificamos como aberrante el supuesto lógico y el aparente beneficio social con el que se pretende sustentar y defender la estabilidad y/o la rigidez laboral en su calidad de política pública en materia social y económica, toda vez que atentan contra leyes básicas de la realidad humana, como persona social, y sobre todo contra leyes de la economía de mercado. En este ensayo se arguye, además, que la estabilidad y la rigidez laborales son demagógicas, porque trafican con un derecho natural de la persona humana, y sofistas, porque parten de bases falsas o erróneas, no acordes con la realidad.

\section{ERRORES DE CONCEPTO DE LA ESTABILIDAD LABORAL}

El gran error de concepto, que, a pesar de no aparecer expuesto, está implícitamente incluido en las razones sociales con las que se pretende justificar la estabilidad y la rigidez laboral, es que el patrón o empresario es un loco enemigo del trabajador, que no hace empresa para ganar dinero, sino para disfrutar del sádico placer de contratar personal para luego despedirlo. Ello es un absurdo, porque el empresario lo último que hace es despedir al buen

2. Con el Decreto Legislativo 18471 del 10 de noviembre de 1970. El Decreto Legislativo 22126 del 21 de marzo de 1978 es de Morales Bermúdez.

3. El artículo 48 y los dispositivos legales 18471, 22126 y 24514 les dieron a los trabajadores estabilidad laboral absoluta. 
trabajador: del que prescinde es del malo, en cumplimiento de la ley de la selección de la especie del homo laborans.

Lo que todo buen empresario hace es tratar de reemplazar a sus malos colaboradores por otros buenos, para, de esta manera, contar con un mejor equipo de trabajo que le permita producir más y mejores productos o prestar más y mejores servicios que los que producen o prestan sus competidores, de modo que pueda obtener mayores utilidades. Dicho en pocas palabras, lo que motiva, financia y permite a los empresarios generar más o menos puestos de trabajo es el éxito de su negocio, porque, cuanto mayor sea el éxito que tenga, más grande querrá que sea. Y, al tener éxito, contará con la capacidad económica necesaria para hacer realidad su deseo de crecer.

La mayor o menor suma de estos éxitos individuales a la economía de cada país es la "mano mágica" de Adam Smith, que va determinando el grado de adelanto o de desarrollo que dicho país va logrando; y es una buena medida del éxito con el que está resolviendo el permanente problema de incorporar a las "nuevas generaciones" a la vida económica, creando nuevos puestos de trabajo que permitan absorber nuestro continuo incremento poblacional.

Otro grave error de concepto de los defensores de la estabilidad y la rigidez laborales es que no se dan cuenta de que, por su intermedio, se hipoteca el futuro del Perú en aras del presente. ¿Por qué decimos esto? Por la respuesta que surge de la siguiente pregunta: ¿a quién beneficia la estabilidad laboral? Pues la estabilidad laboral solo beneficia al trabajador que ya tiene trabajo, en perjuicio de los que no cuentan con él, así como la remuneración mínima vital solo beneficia a quienes valen el sueldo mínimo para las empresas, en detrimento de quienes no lo valen, pero que buscan emplearse.

Para graficar este absurdo, pongamos un ejemplo muy sencillo, usando la misma lógica con que se pretende justificar el supuesto beneficio, logro o conquista social de la estabilidad laboral. ¿Por qué no se les otorga, con el mismo derecho y por las mismas razones, estabilidad laboral a los jugadores de la selección nacional de fútbol de 1970 o a nuestra selección nacional de vóley (subcampeona mundial en 1982 y medalla de plata en las olimpiadas de 1988)?

Pensamos que, dadas las actuales circunstancias, nuestros arietes del 70 y nuestras matadoras del 82 tendrían todo el derecho del mundo a solicitarlo. Lo único malo sería que, en el caso de concederles el beneficio de la estabilidad laboral a la selección de fútbol del 70 y a la de vóley del 82, el Perú no volvería a clasificar nunca más a ninguna otra justa mundialista. Y no porque los futbolistas y las matadoras sean malos, sino por el hecho de que, a causa del deterioro físico que produce el inexorable paso del tiempo en todo ser humano, particularmente en todo deportista, al enfrentarse a adversarios mucho más jóvenes que ellos serían siempre superados y vencidos. La vida es un continuo devenir, y no podemos, absurda y demagógicamente, pretender detener el presente de forma indefinida.
Un tercer gran error en el que se incurre con el concepto de la estabilidad laboral es que atenta contra una ley general del mercado: la competencia, que, como función, proviene a su vez de otro principio o ley universal, vigente conceptualmente, desde las contribuciones de Charles Darwin, para todo el planeta: la ley de selección de la especie.

La naturaleza, de modo sabio, ha dispuesto de una ley inexorable: frente al reto de la vida solo sobrevive el más capaz, porque de esta forma se obtiene una especie cada vez mejor capacitada para enfrentar este gran reto de la vida. Podríamos apelar a la evolución darwiniana para afirmar que en el mundo de los negocios pasa exactamente lo mismo. En él, la ley de selección de la especie del homo economicu se ha traducido en la aplicación de la función de la competencia, que va seleccionando a los empresarios y trabajadores más capaces o exitosos, a expensas, natural y estructuralmente, de los menos capaces y exitosos.

La vigencia de la estabilidad laboral frena y pone en peligro el crecimiento económico e industrial del Perú, al desconocer o no tomar en cuenta la vital importancia que tiene la función de la competencia en el libre mercado y en el comercio internacional para garantizar el desarrollo económico de cualquier país, provisto de las instituciones afines. Porque, nos guste o no, el mundo actual transita por las vías del industrialismo, y este tiene una lógica y reglas o leyes básicas que no podemos impunemente transgredir, ya que el precio que se paga por hacerlo es muy caro, y se llama subdesarrollo.

La función de la competencia es una característica del sistema de libre mercado con la que tropezamos una y otra vez. La competencia se da en todos los ámbitos y en cada nivel del quehacer humano, y es el ingrediente que tonifica y da vigor al sistema. Así, tenemos que, en el mercado laboral de libre competencia, la existencia de otros patronos de los que un trabajador puede conseguir empleo protege a este de cualquier abuso de su empleador: y el empresario, a su vez, se ve protegido de la explotación de sus trabajadores por la existencia de otros individuos a los que puede emplear.

Para comprender mejor esto, tomemos nuevamente el ejemplo de deportes populares como el fútbol y el vóley, cuyas leyes propias incluyen leyes naturales (como la ley de la gravedad, que hace que la pelota tenga peso y caiga a tierra) que nadie cuestiona. De igual modo, no debemos perder el tiempo tratando de modificar las leyes o reglas de la economía, sea porque no nos gustan o porque nos parecen injustas bajo la óptica marxista o socialista, o según nuestro particular punto de vista. Antes, por el contrario, hemos de entender las reglas de la naturaleza y del mercado, y, dentro de ellas, esforzarnos más por ser los mejores y triunfar en la lucha por la vida, enmarcados por los límites impuestos por la ley, ante la que sabemos que, en principio, somos iguales.

La estabilidad y la rigidez laborales ya tienen tiempo más que suficiente con nosotros, de forma que es posible analizar objetivamente si sus efectos han sido positivos o negativos para el desarrollo del Perú. Sin lugar a dudas, 
podemos decir que han tenido escasos efectos positivos, por no decir ninguno, y sí muchos negativos. Una gran parte de estos últimos se debe a que provienen del marxismo, que, como filosofía política que apela a la lucha de clases y, a través de la planificación central, al estatismo económico, inyectan odio en la sociedad y presentan la relación laboral como un enfrentamiento permanente entre patronos (explotadores) y asalariados (explotados). Y es así como se inculca en los trabajadores el sentimiento de ser "expoliados" por su enemigo, el patrono explotador.

Una relación laboral así sería insostenible. Y más importante es que, en la realidad del Perú, es falsa. Igual de relevante, si no lo es más, es que lo mencionado en el párrafo anterior resulta sumamente negativo y peligroso. Negativo porque frena el avance económico del país y peligroso porque frustra el desarrollo ético-moral de los trabajadores como seres humanos. Esto es crítico, ya que, al fomentarse el odio y el conflicto social, promoviendo así el rencor, se impide que el trabajador vea el trabajo como lo que realmente es: una fuente continua y permanente de realización del ser humano, que le permite lograr mejores condiciones de vida para él y su familia y, simultáneamente, alcanzar posiciones sociales más altas. Al presentarse una imagen distorsionada del trabajo y de sus frutos, se disminuye o frustra el natural sentimiento de orgullo que toda persona tiene por una labor bien realizada, y se le quita el deseo de mostrar a los demás los logros alcanzados con su esfuerzo personal. Se resta dignidad.

El trabajo dignifica al ser humano. Debe ser una fuente de estima, respeto y consideración, no de odio. Porque el odio envenena a las personas e impide el progreso tanto de ellas como de su país. Por ello, es bueno recordar la exhortación al trabajo que contiene la parábola sobre los talentos (Evangelios de Mateo 25:14-30; y de Lucas 19:11-27) y el mandato que encierra: cultivar, cuidar y fructificar los dones individuales o talentos que cada ser humano ha recibido del Señor. Y esto solo se logra trabajando esforzadamente. Estamos enfrentando a peruanos contra peruanos, y, como dice el Evangelio: "Reino dividido contra sí mismo deviene en desolación (Mateo 12:25), y casa dividida contra sí misma cae en ruinas (Lucas 11:17)". Es por eso lamentable y perjudicial para el desarrollo económico del Perú que la siguiente frase refleje una buena parte de la realidad nacional: "¿Quieres tener mañana un enemigo? Genera un puesto de trabajo".

Otra consecuencia negativa de la rigidez laboral es que atenta contra una de las reglas básicas de la lógica de desarrollo del industrialismo ${ }^{4}$, porque frena la natural movilidad que debe existir en el sector laboral, al no permitir que las nuevas generaciones se integren de forma continua al mercado laboral y vayan ocupando sus puestos de modo fluido, ya que, al cambiar de centro de trabajo, van mejorando y se van capacitando, al tomar experiencia

4. Ver El industrialismo y el hombre industrial (1996) de Clark Kerr, John T. Dunlop, Frederick H. Harbison y Charles A. Myers. y comparar a las empresas para las que han laborado y laboran. De esta manera, la rigidez laboral produce vacíos o baches generacionales en la gran mayoría de los empleos, agravándose en aquellos puestos cuya naturaleza exige mayor rotación o renovación de personal, como son los que requieren un elevado porcentaje de esfuerzo físico (minería, pesca, construcción civil, entre otros).

Otro efecto nocivo que trae la rigidez laboral es que genera una distorsión en la curva salarial de las empresas, las cuales, para eludirla, recurren a los services. Con ello, el perjudicado es el trabajador, porque, si el puesto vale 100 , es ese monto el que la compañía paga al service, pero este solo entrega 70 al trabajador y se queda con 30 para cubrir sus costos operativos. A modo de ejemplo, el puesto de portero para una empresa cualquiera debería ser un puesto de tránsito, de alta rotación, porque no requiere mayor calificación del trabajador que lo ocupa, que es, por lo general, una persona que recién empieza a laborar. Por ello, su remuneración no debería exceder el salario mínimo. Pero, como el portero tiene estabilidad laboral, la organización no solo no puede despedirlo y contratar en su lugar a otra persona que sí acepte el sueldo mínimo, sino que, además, se ve obligada a concederle todos los aumentos de sueldo que disponga el Gobierno de turno. Como todos sabemos, el dinero para estos aumentos salariales no sale del aire, sino del precio de venta del producto o servicio de la firma. Así, se está contribuyendo al incremento innecesario de costos, en detrimento de la competitividad empresarial.

Sumado a ello, no debemos olvidar la gran frustración que debe sentir el trabajador con deseos y ansias de superación y que recién ocupa el cargo de portero al comprobar que su salario solo le alcanza para cubrir sus necesidades básica y que no puede hacer nada para remediarlo, porque son escasas y difíciles las perspectivas de llegar a puestos mejor remunerados, debido a que la estabilidad laboral se lo obstaculiza o impide, pues inmoviliza a los demás trabajadores en sus puestos. Y, si a esto le agregamos los elevados costos de ser formal, podemos entender por qué el $70 \%$ de la actividad económica nacional es informal.

\section{LA INDISPENSABLE MOVILIDAD LABORAL PARA GENERAR EL DESARROLLO INDUSTRIAL}

Cuando, con relación al deporte, se habla de la natural movilidad del factor humano, esto nos parece del más elemental sentido común; pero si se trata del campo laboral, nos negamos a aceptarla terca y tontamente, y aducimos para ello las más absurdas y demagógicas razones. Ello, sin darnos cuenta de que cada minuto que perdemos transitando en la dirección equivocada son oportunidades de desarrollo que desperdiciamos y que no volverán. Es por tal motivo que consideramos un deber ineludible del Estado el tratar de fortalecer el proceso de industrialización del país, reformando íntegramente el mercado laboral, en lugar de atentar contra sus leyes naturales. 
Todas estas ineficiencias se trasladan finalmente al costo del producto o del bien prestado, de manera que nuestros bienes y servicios están compitiendo en desventaja con los bienes y servicios de otros países que no han alterado el normal desarrollo generacional de su fuerza laboral. La única forma para progresar realmente con la que cuenta una nación es generando más riqueza. Y esto solo se logra cuando existe amplia libertad económica y reglas de juego estables, edificadas sobre bases institucionales sólidas y reales, que no permitan el éxito de algunos solamente, sino el de todos según su esfuerzo. Es decir, hablamos de mercados realmente libres circundados por instituciones inclusivas.

En todos los países del mundo, un pequeño grupo de pioneros señala el ritmo de crecimiento económico y determina el curso de los acontecimientos. En las naciones que se han desarrollado más rápida y prósperamente, una minoría de individuos emprendedores y arriesgados ha avanzado constantemente, creando oportunidades económicas y puestos de trabajo para que las aprovechen aquellos que quieran imitarlos. Estos generadores de riqueza han hecho posible que la mayor parte de la población aumente su productividad y riqueza personal y la de sus países. Esta élite no tiene por qué ser simpática, cultivada, inteligente, blanca, negra, china o chola solo trabajar diligentemente en la creación de riqueza. Y de su trabajo se beneficia el conjunto de la sociedad; es decir, son las gallinitas de los huevos de oro. Pero, si el Gobierno desalienta a estos dinamizadores de la economía, entonces preferirán no trabajar y dedicarse a otras actividades culturales o deportivas. Y si, además, los amenaza y atemoriza, decidirán irse al extranjero a poner los huevos de oro.

La pereza y la falta de espíritu emprendedor aparecen cuando el trabajo duro y el asumir riesgos no reciben su justa recompensa, que es la que da el mercado, no la que pretenden fijar los demagogos, políticos y/o burócratas estatales ${ }^{5}$. De esta forma se crea una generación de trabajadores que tienen poco espíritu de iniciativa y que quieren que se les diga con toda exactitud lo que han de hacer; son indolentes, poco cooperativos y, por lo tanto, de muy escasa productividad. No son útiles ni a su nación ni a ellos mismos. La realidad del país no es la que pretenden los políticos, es otra, y es de cara a ella que se debe legislar, para no ser presa de nuestros propios errores.

En aquel país donde los salarios, en su calidad de precios, son flexibles y pueden adaptarse a los resultados de las empresas, nuevas o no, la ocupación se incrementa. Pero allí donde los salarios son rígidos, sobre todo en lo referente a reglamentaciones, convenciones colectivas, presiones sindicales, privilegios gremiales, etcétera, la ocupación desaparece o disminuye drásticamente. La desocupación no es un accidente económico ni un mal endémico: es la consecuencia directa de la sobreprotección del Estado, que beneficia en gran parte solo a los que ya tienen trabajo y a líderes sindicales.

\section{REFLEXIONES FINALES}

Dos cerrojos que impiden el crecimiento económico del país son la estabilidad laboral y la remuneración mínima vital. Esta última, además de fomentar el empleo de quienes no tienen mayor productividad laboral, frustra el nacimiento o ingreso al mercado de nuevos empresarios, quienes, generalmente al inicio de sus actividades económicas, no están en condiciones de poder pagar el salario mínimo que impone el Estado. O de hacerlo, en todo caso, a quienes no lo valen. Entonces, la remuneración mínima vital no genera empleo ni empresarios, de quienes el país depende para la creación de riqueza y de trabajo. Sin embargo, como conceptos, la remuneración mínima vital en particular y la estabilidad laboral en general son herramientas valiosas para los políticos demagogos, que regalan lo ajeno (porque ellos no lo pagan) porque les rinde beneficios políticos.

¿En qué momento nuestros legisladores y políticos se darán cuenta de que deben legislar en bien del país y de sus generaciones futuras, y no solamente en función de sus propios incentivos políticos y económicos? ¿Cuándo entenderemos los peruanos que es nuestro deber (para con nosotros y nuestras futuras generaciones) y nuestro derecho (como generación actual) el exigir a nuestros representantes políticos que legislen a favor del desarrollo del país?

5. Quienes deberían comprender que no se hace patria ni se llega al Cielo regalando lo ajeno. 